\title{
A simplified distillation-based sulfur speciation method for sulfidic soil materials
}

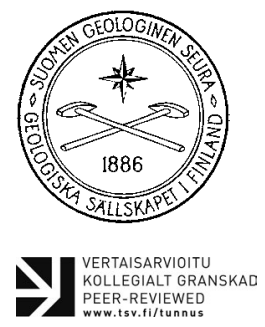

\author{
Krister Dalhem ${ }^{\mathrm{I}^{*}}$, Stefan Mattbäck ${ }^{\mathrm{I}}$, Anton Boman ${ }^{2}$ and \\ Peter Österholm ${ }^{\mathrm{I}}$ \\ ${ }^{1}$ Department of Geology and Mineralogy, Åbo Akademi University, FI-20500, \\ Turku, Finland \\ ${ }^{b}$ Geological Survey of Finland, FI-67101, Kokkola, Finland
}

\begin{abstract}
Speciation of inorganic sulfur species, mainly pyrite and metastable iron sulfides by operationally defined methods, is widely used for risk assessment of acid sulfate soils by quantifying the acidity producing elements, as well as for general characterisation of marine sediments and subaqueous soils. "Traditional" sulfur speciation methods commonly use highly specialised glassware which can be cumbersome for the operator, or, require long reaction times which limit the usability of the method. We present a simplified method which has a sufficiently low limit of detection $(0.002 \%)$ and quantitation $(0.006 \%)$ required for the analysis of sulfidic sulfur in acid sulfate soil materials. Commercially available sulfide reagents were used for determining reproducibility and the method was assessed on natural sulfidic soil materials, including fine to coarse grained soil materials as well as sulfide bearing peat, with a large variation of metastable sulfide and pyrite content.
\end{abstract}

Keywords: Sulfur speciation, acid sulfate soils, pyrite, peat, limit of detection

*Corresponding author (e-mail: krister.dalhem@abo.fi)

Editorial handling: Pertti Sarala (e-mail: pertti.sarala@gtk.fi)

\section{Introduction}

Determination of sulfur species is widely used for understanding the geochemical cycle of sulfur in sediments as well as a tool for risk assessment of sulfidic materials. In general, sulfur speciation methods involve sequentially liberating $\mathrm{S}$ as $\mathrm{H}_{2} \mathrm{~S}_{(\mathrm{g})}$ from reduced inorganic sulfur species, using strongly acidic reagents under anoxic conditions. By precipitating the liberated sulfidic $S$ in an alkaline trapping solution, the recovered $S$ can be determined by the means of e.g. iodometric titration (Canfield et al., 1986; Hsieh et al., 2002; 
Burton et al., 2008). These methods are considered operationally defined as the evolved $S$ species are reagent and procedure dependent and do not necessarily reflect the actual $S$ species present in the sample (Rickard \& Morse, 2005). Nevertheless, established analytical procedures distinguish between acid volatile sulfides (AVS), chromium reducible sulfur (CRS) and elemental sulfur (ES) (e.g. Fossing \& Jørgensen, 1989; Hsieh \& Yang, 1989; Backlund et al., 2005).

AVS is generally regarded to comprise of mainly the metastable iron sulfides mackinawite $(\mathrm{FeS})$ and greigite $\left(\mathrm{Fe}_{3} \mathrm{~S}_{4}\right)$ (e.g. Boman et al., 2008) but may also include aqueous iron sulfide complexes and dissolved $\mathrm{S}^{2-}$ species (e.g. $\mathrm{H}_{2} \mathrm{~S}, \mathrm{HS}$ ) (Rickard $\&$ Morse, 2005). AVS-S is commonly dissolved using hydrochloric acid $(\mathrm{HCl}$; reaction 1$)$ with ascorbic acid added to prevent oxidation of AVS by $\mathrm{Fe}(\mathrm{III})$ (Hsieh et al., 2002). Pyrite $\left(\mathrm{FeS}_{2}\right)$ is most often dissolved using an acidic chromium chloride $\left(\mathrm{CrCl}_{2}\right)$ solution, first used by Zhabina \& Volkov (1978), (reaction 2), hence the term chromium reducible sulfur (CRS). If elemental sulfur $\left(\mathrm{S}_{8}{ }^{0}\right)$ is not removed prior to pyrite dissolution, pyrite and elemental sulfur can be determined in a combined fraction, termed hot chromium reducible sulfur ( $\mathrm{HCrS})$, by using $\mathrm{CrCl}_{2}$ in sub-boiling $\left(60^{\circ} \mathrm{C}\right)$ conditions (Fossing \& Jørgensen, 1989). Elemental sulfur can, however, also be separately removed using an organic solvent and then dissolved using $\mathrm{CrCl}_{2}$ and sub-boiling $\left(60^{\circ} \mathrm{C}\right)$ conditions (reaction 3). Dissolution of reduced sulfur species can be illustrated by the simplified reactions:

$$
\begin{aligned}
& \mathrm{FeS}_{(\mathrm{s})}+2 \mathrm{HCl}_{(\mathrm{l})} \rightarrow \mathrm{H}_{2} \mathrm{~S}_{(\mathrm{g})}+\mathrm{Fe}_{(\mathrm{l})}^{2+}+2 \mathrm{Cl}_{(\mathrm{l})}^{-} \\
& \mathrm{FeS}_{2(\mathrm{~s})}+2 \mathrm{CrCl}_{2_{(\mathrm{l})}}+4 \mathrm{HCl}_{(\mathrm{l})} \rightarrow 2 \mathrm{H}_{2} \mathrm{~S}_{(\mathrm{g})}+\mathrm{Fe}_{(\mathrm{l})}^{2+}+2 \mathrm{Cl}^{-}+2 \mathrm{CrCl}_{3(\mathrm{l})} \\
& \mathrm{S}_{(\mathrm{s})}^{0}+2 \mathrm{HCl}_{(\mathrm{l})}+2 \mathrm{CrCl}_{2(\mathrm{l})} \rightarrow \mathrm{H}_{2} \mathrm{~S}_{(\mathrm{g})}+2 \mathrm{Cl}_{(\mathrm{l})}^{-}+2 \mathrm{CrCl}_{3(\mathrm{l})}
\end{aligned}
$$

where "FeS" represents any metastable iron sulfide present in the sample, "FeS 2 " represents pyrite and " $\mathrm{S} 0$ " represents elemental sulfur.

Sulfur speciation methods traditionally require expensive, fragile, and cumbersome glassware which limit the possibility for multiple simultaneous analyses and sets a high demand on the operator. Simpler, inexpensive equipment setups, such as the diffusion method by Burton et al. (2008), offer more robust and versatile options for large sample sets, whilst still capable of reasonable precision and accuracy. However, the aforementioned diffusion method demands longer reaction times than distillation methods and is inadequately designed to, for example, dissolve $S$ species from lightweight materials, e.g. peat, as thorough mixing using magnetic stirring is not possible.

Sulfidic soils and sediments that are able to produce sulfuric acid upon oxidation and can leach significant quantities of acidity and potentially toxic metals to water courses and cause corrosion on infrastructure are called acid sulfate (AS) soils $(\mathrm{pH}<4)$. Such soils are widely spread around the world, mainly along the coastlines of Asia, Australia, Africa, Latin-America and in Europe (Andriesse \& Van Mensvoort, 2006). It is often of significant interest within land use and water management (e.g. agriculture, dredging, infrastructure) to characterise AS soils and assess their potentially negative environmental effects. In order to do this, it is crucial to quantify the different sulfur species that are the main drivers for acidification and metal leaching. Predominately these are reduced species such as metastable iron sulfides (stoichiometrically close to $\mathrm{FeS}$ ) and pyrite $\left(\mathrm{FeS}_{2}\right)$ that, when oxidised, produce sulfuric acid according to the following simplified reactions (e.g. Singer \& Stumm, 1970; Kirby \& Cravotta, 2005): 


$$
\begin{aligned}
& 4 \mathrm{FeS}_{(\mathrm{s}, \mathrm{aq})}+9 \mathrm{O}_{2_{(\mathrm{g})}}+10 \mathrm{H}_{2} \mathrm{O}_{(\mathrm{l})} \rightarrow 4 \mathrm{Fe}(\mathrm{OH})_{3(\mathrm{~s})}+4 \mathrm{SO}_{4}^{2-}{ }_{(\mathrm{l})}+8 \mathrm{H}_{(\mathrm{l})}^{+} \\
& 4 \mathrm{FeS}_{2(\mathrm{~s})}+15 \mathrm{O}_{2_{(\mathrm{g})}}+14 \mathrm{H}_{2} \mathrm{O}_{(\mathrm{l})} \rightarrow 4 \mathrm{Fe}(\mathrm{OH})_{3(\mathrm{~s})}+8 \mathrm{SO}_{4}^{2-}{ }_{(\mathrm{l})}+16 \mathrm{H}_{(\mathrm{l})}^{+}
\end{aligned}
$$

The World Reference Base (WRB) international standard for soil classification states that hypersulfidic material (i.e. soil material capable of severe acidification as a result of the oxidation of inorganic sulfidic compounds) has a diagnostic criterion of $\geq 0.01 \%$ inorganic sulfidic $\mathrm{S}$ per dry mass, and a $\mathrm{pH} \geq 4$ that undergoes a drop in $\mathrm{pH}$ to $<4$ when incubated aerobically at field capacity until the $\mathrm{pH}$ drop is $\geq 0.5$ units, or until a stable $\mathrm{pH}$ is reached (Sullivan et al., 2010; IUSS Working Group WRB., 2015; Isbell \& National Committee on Soil and Terrain, 2016). Using current sulfur speciation methods (e.g. Zhabina \& Volkov, 1978; Canfield et al., 1986; Backlund \& Boman et al., 2005; Gröger et al., 2009) it is possible to separate and quantify reduced sulfur species with good precision and accuracy from fine-grained $\left(\mathrm{d}_{50 \%}\right.$ grain size $<63 \mu \mathrm{m})$ AS soil materials, however, the limits of quantitation (LoQ) and determination (LoD) are often not stated. Recent studies (Mattbäck et al., 2017) have also brought to attention coarse-grained $\left(\mathrm{d}_{50 \%}\right.$ grain size $\left.\geq 63 \mu \mathrm{m}\right)$ AS soil materials with very low sulfidic $S$ concentrations $(0.01-0.10 \%)$ that have an acidifying effect on the local environment. There is therefore a need for a simplified and robust sulfur speciation method with a determined LoQ of $\leq 0.01 \%$ sulfidic $S$ and by which large sample sets can be analysed. In this study, such a simplified setup constructed from easily available inexpensive materials is presented by which sequential sulfur speciation is possible through distillation, thus enabling faster analyses than by diffusion methods. Simultaneously the method is precise and accurate enough to suit the need for both detailed sulfur speciation studies as well as risk assessment for a versatile range of sulfidic materials including fineto coarse-grained soils as well as peat.

\section{Material and methods}

\subsection{Apparatus for the simplified sulfur speciation method}

The distillation apparatus (Fig. 1) is constructed from conventional $50 \mathrm{~mL}$ conical polypropylene centrifuge tubes. The centrifuge tube caps are fitted with acid resistive tubing plugged with luer ports and luer-lock stopcocks. Commercially available options of the modified tube-caps (OmniTop Sample Tubes ${ }^{\mathrm{TM}}$, PAW Bioscience) were also tested, and both setups, when properly assembled, are pressure tight up to $200 \mathrm{kPa}$, far above pressures reached during distillation. Collection vessels were also constructed using polypropylene centrifuge tubes, with tube caps fitted with a luer-lock stopcock connected to a glass pipette for bubbling the liberated $\mathrm{H}_{2} \mathrm{~S}_{(\mathrm{g})}$ under the liquid level of the trapping solution. The modified tube-caps and tubing can be cleaned and re-used. This simplified setup allows efficient delivery of reagents to the reaction vessel and $\mathrm{N}_{2(\mathrm{~g})}$ assisted transport of the liberated $\mathrm{H}_{2} \mathrm{~S}_{(\mathrm{g})}$ to the collection vessel. A gas delivery system is required, preferably with several outlet ports for multiple simultaneous distillations. $\mathrm{N}_{2(\mathrm{~g})}$ is also used to create an anoxic environment and to deoxygenise the trapping solution and other reagents used in the distillation process. Magnetic stirrers are needed to ensure complete reaction between sample and reagents, as well as a heating bath for reaching temperatures up to $60{ }^{\circ} \mathrm{C}$ for $\mathrm{HCrS}$ (including pyrite and elemental sulfur) distillations. The reaction vessel can sustain up to boiling-point temperatures thus enabling shorter reaction times compared to cold distillation methods. 

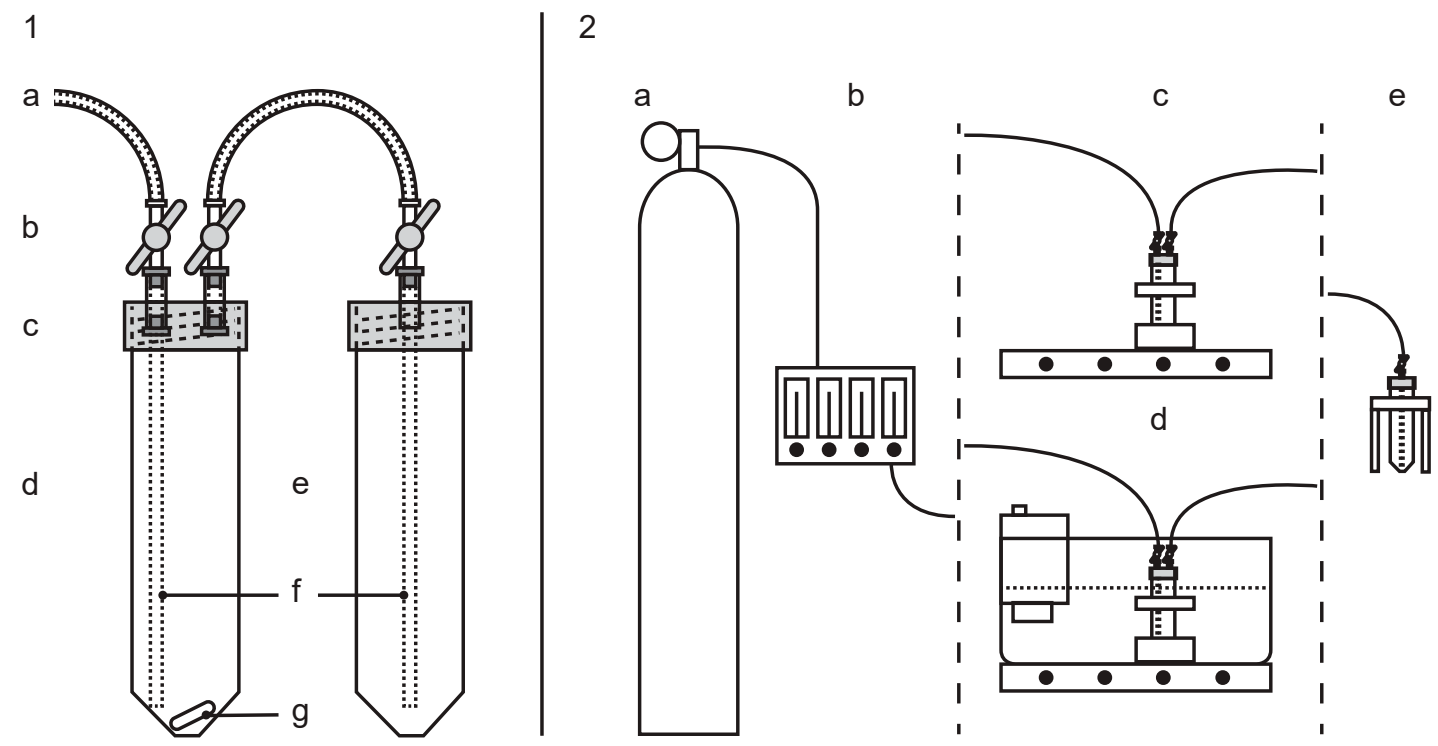

Figure 1. 1) Schematic of reaction and collection vessels: a) tubing for gas-flow, b) luer-lock stopcocks, c) polypropylene screw caps, d) $50 \mathrm{~mL}$ polypropylene centrifuge tube as reaction vessel, e) $50 \mathrm{~mL}$ polypropylene centrifuge tube as collection vessel, f) tubing/glass pipette, and g) stirring magnet. 2) Schematic of distillation setup: a) $\mathrm{N}_{2}$-gas bottle, b) flow meter, c) distillation setup with reaction vessel on a stirring plate, d) distillation setup with reaction vessel in a water bath on a stirring plate, and e) collection vessel.

\subsection{Standards and samples}

Methodology and apparatus were tested using commercially available laboratory reagents in order to compare the simplified sulfur speciation method with previous methods and to establish limits of detection and quantitation. The limit of detection (LoD; at a 95\% confidence level) was calculated as 3.3 times $(\mathrm{F})$ the standard deviation of the method blank, divided by the slope of the regression gradient (b) of the range of standards analysed; and the limit of quantitation (LoQ) as 10 times (F) the standard deviation of the blank divided by the slope (b), in accordance to equation I by Shrivastava \& Gupta (2011):

$$
\text { LoD or LoQ }=\frac{F \times S D}{b}
$$

\subsubsection{Artificial samples}

Commercially available iron disulfide $\left(\mathrm{FeS}_{2}\right)$ powder $(44 \mu \mathrm{m})$ was used to determine the limits of quantitation and detection of the $\mathrm{HCrS}$ (hot chromium reducible sulfur) method (e.g. the fraction containing mainly pyrite and minor amounts of elemental sulfur). The pyrite standard was gravimetrically weighed and mixed with hydrous magnesium silicate (talc, $\left.3 \mathrm{Mg}^{*} 4 \mathrm{SiO}_{2}{ }^{*} \mathrm{H}_{2} \mathrm{O}\right)$ powder $(44 \mu \mathrm{m})$ in a range of concentrations (c. 0.08-5.00\%). The exact sulfur content of the talc was determined by ICP-OES (aqua regia). This talc powder, without added pyrite, worked as the method blank. Similarly prepared standards have been used previously (e.g. Backlund \& Boman, 2005; Burton et al., 2008; Gröger et al., 2009).

To determine the precision at low $S$ concentrations, an approx. $33 \mathrm{mg} / \mathrm{L}$ sulfide standard solution was prepared using sodium sulfide nonahydrate $\left(\mathrm{NaS}_{2}{ }^{*} 9 \mathrm{H}_{2} \mathrm{O}\right)$ and a sulfide anti-oxidation buffer solution ( $\mathrm{SAOB}$ ). The $\mathrm{SAOB}$ was prepared by adding $1 \mathrm{~L}$ of deoxygenated $2 \mathrm{M} \mathrm{NaOH}$ to $20 \mathrm{~g}$ ascorbic acid in a $1 \mathrm{~L} \mathrm{~N}_{2}$-purged volumetric flask (Glaister et al., 1984). In a separate $\mathrm{N}_{2}$-purged flask, 
$\mathrm{NaS}_{2}{ }^{*} 9 \mathrm{H}_{2} \mathrm{O}$ was added and dissolved in SAOB and made up with additional SAOB until the sulfide concentration was approximately $33 \mathrm{mg} / \mathrm{L}$. The exact sulfide concentration $(34.7 \mathrm{mg} / \mathrm{L}$; standard deviation $0.003 \mathrm{mg} / \mathrm{L}$ ) in the freshly prepared sulfide standard solution was determined by endpoint $0.1 \mathrm{M}$ lead perchlorate titration (in quadruplicates) using an ion-selective silver/sulfide electrode. The SAOB sulfide standard solution was then analysed using the AVS procedure. Three different AVS speciations were performed in quadruplicates using varying amounts of sulfide standard solution $(1 \mathrm{~mL}, 5 \mathrm{~mL}$ and $15 \mathrm{~mL})$ corresponding to approximately $0.034 \mathrm{mg}$, $0.17 \mathrm{mg}$ and $0.50 \mathrm{mg}$ of sulfidic $S$ to be distilled.

\subsubsection{Natural samples}

Hypersulfidic soil material was collected from the reduced monosulfidic (i.e. the black/dark grey parent material known to be a significant source of AVS-S (Rickard \& Morse, 2005) horizon from four different sites along the West Coast of Finland (Fig. 2): a) subaqueous gyttja clay from an estuary $\left(63^{\circ} 3.49^{\prime} \mathrm{N}, 21^{\circ} 38.99^{\prime} \mathrm{E}\right)$, b) silty clay from an agricultural field $\left(63^{\circ} 2.84^{\prime} \mathrm{N}, 21^{\circ} 42.69^{\prime} \mathrm{E}\right)$, c) coarse silt from a wetland $\left(64^{\circ} 55.24^{\prime} \mathrm{N}, 25^{\circ} 31.29^{\prime} \mathrm{E}\right)$ and d) subaqueous sand from an exposed beach deposit $\left(63^{\circ} 36.79^{\prime} \mathrm{N}, 22^{\circ} 29.83^{\prime} \mathrm{E}\right)$. The estuary is large and shallow $\left(16 \mathrm{~km}^{2}, 19.2 \mathrm{M} \mathrm{m}^{3}\right)$ and is recipient to two major river catchments that drain known coastal lowland AS soils. The agricultural field is part of a polder, an embankment continuously drained by pumping stations, currently situated c. $0.5 \mathrm{~m}$ below current sea level. The parent material consists of Holocene hypersulfidic marine sediments which have, due to intensive drainage since the 1950's, formed an active agricultural AS soil. The site has been extensively studied by e.g. Nordmyr et al. (2006), Boman et al., (2008) and Dalhem et al., (2019). The wetland is situated in proximity $(<5 \mathrm{~km})$ to the shoreline and is mainly consisting of postglacial littoral deposits. The exposed beach deposit is situated on the sea-shore boundary and is experiencing alternating submerged (high water)

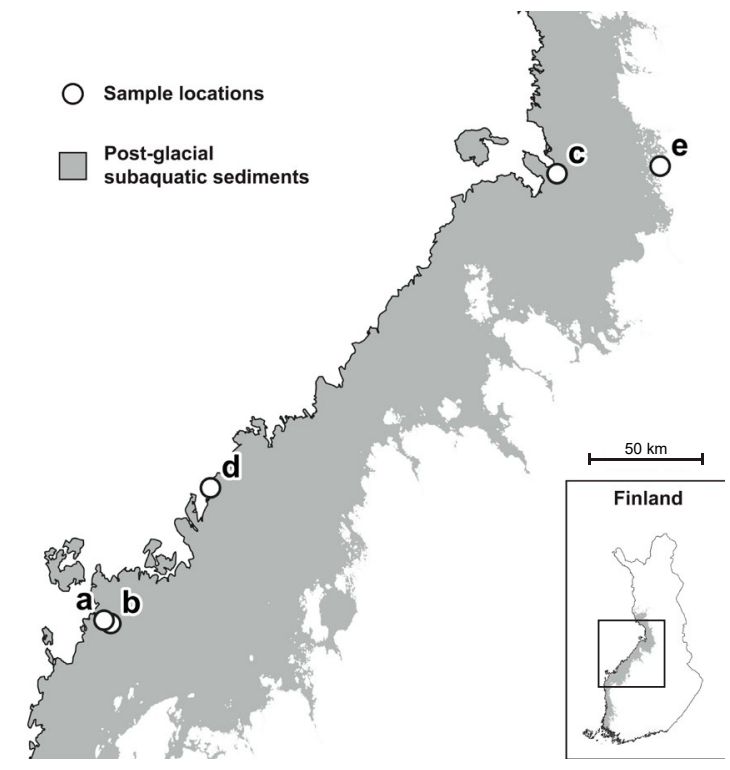

Figure 2. Map of sample locations along the West Coast of Finland: a) gyttja-clay, b) silty gyttja-clay, c) coarse silt, d) sand and e) peat.

and dry conditions (low water), which can alter the shoreline with nearly 100 meters.

Hypersulfidic peat was collected from the reduced horizon from a peat production area $\left(64^{\circ} 57.43^{\prime} \mathrm{N}, 26^{\circ} 29.08^{\prime} \mathrm{E}\right)$ situated c. $85 \mathrm{~m}$ above current sea level (Fig. 2 ; e). The peat $(\sim 0.9 \mathrm{~m}$ thick) at the site is mainly underlain by Holocene hypersulfidic sand and silt, and occasionally gyttja clay, and the area is known to produce highly acidic discharges.

The samples were collected in large 5-10 L containers and frozen immediately after transport. Before analysis, the samples were thawed in an $\mathrm{N}_{2(\mathrm{~g})}$ filled glove box, thoroughly homogenized, and subsampled into $50 \mathrm{~mL}$ polypropylene centrifuge tubes.

\subsection{Sequential extraction procedure for reduced sulfur species}

The presented sequential extraction procedure is operationally defined for different reduced sulfur species and can be modified according to the analysis needed. In short, the procedure is carried out in the following way: sample is weighed 
with four-decimal accuracy (300-5000 mg dry weight equivalence; depending on the estimated sulfide concentration) into the reaction vessel and a small $(10 \times 6 \mathrm{~mm})$ stirring rod is added. The distillation apparatus is assembled according to Fig. 1 depending on the need for a heating bath or only magnetic stirring. All reagents are prepared using deionised water and purged with $\mathrm{N}_{2(\mathrm{~g})}$ $10 \mathrm{~mL}$ of an alkaline trapping solution ( $\mathrm{Zn}$-acetate in $2 \mathrm{M} \mathrm{NaOH}, 1: 5$ ratio) is added to the collection vessel and the whole setup is flushed with $\mathrm{N}_{2(\mathrm{~g})}$ for a minimum of 1 minute to ensure an oxygen free environment and an oxygen free trapping solution. Reagent is added to the sample through the luerlock stopcocks and the flow of $\mathrm{N}_{2(\mathrm{~g})}$ is continued with a rate of approximately $3-5$ bubbles per second for transferring the evolved $\mathrm{H}_{2} \mathrm{~S}_{(\mathrm{g})}$ to the trapping solution. A precipitate of $\mathrm{ZnS}$ (reaction 6) should now be clearly visible in the collection vessel and the extracted/recovered $\mathrm{S}$ can be determined using the standard iodometric titration procedure (APHA, 1976).

$$
2 \mathrm{H}_{2} \mathrm{~S}_{(\mathrm{g})}+2 \mathrm{Zn}_{(\mathrm{l})}^{2+} \rightarrow 2 \mathrm{ZnS}_{(\mathrm{s})}+4 \mathrm{H}_{(\mathrm{l})}^{+}
$$

For this study, the distillation method was only used to sequentially extract the AVS and HCrS fractions from natural samples as well as separately from sulfidic standards in order to determine method accuracy and precision according to the simplified flowchart detailed in Fig. 3. In the first step, AVS was extracted for 2 hours using $10 \mathrm{~mL} 6 \mathrm{M} \mathrm{HCl}$ with $2 \mathrm{~mL} 0.1 \mathrm{M}$ ascorbic acid as inhibitor for $\mathrm{Fe}^{2+}$ oxidation (Hsieh et al., 2002). Before injection to the reaction vessel, the $\mathrm{HCl}$ and ascorbic acid was bubbled with $\mathrm{N}_{2(\mathrm{~g})}$ in order to purge any dissolved oxygen. In the second step, pyrite-S together with elemental sulfur (i.e. $\mathrm{HCrS}$ ) was extracted using filtered $(0.2 \mu \mathrm{m}) 10 \mathrm{~mL} 3 \mathrm{M} \mathrm{CrCl}_{2}$ and by heating at $60{ }^{\circ} \mathrm{C}$ for $2-3 \mathrm{~h}$ on a water bath. Gröger et al. (2009) showed that filtering the $\mathrm{CrCl}_{2}$ solution improves the selectivity of the method as it removes zinc particles from the solution. The $3 \mathrm{M} \mathrm{CrCl}_{2}$ solution was prepared by first dissolving $250 \mathrm{~g}$ of $\mathrm{CrCl}_{3^{*}} 6 \mathrm{H}_{2} \mathrm{O}$ in $500 \mathrm{~mL} 6 \mathrm{M} \mathrm{HCl}$ on a hotplate. The
$\mathrm{CrCl}_{3}$ solution was then deoxygenated in a $1 \mathrm{~L}$ flask and then injected into a $\mathrm{N}_{2}$-purged $1 \mathrm{~L}$ reaction flask containing $100 \mathrm{~g}$ metallic zinc $(250-595 \mu \mathrm{m})$ (modified after Burton et. al., 2008).

Iodometric titration was used to determine the amount of recovered $\mathrm{S}$ as $\mathrm{ZnS}$ in the alkaline $\mathrm{Zn}$-acetate trapping solution and was performed according to the modified guidelines of APHA (1976) detailed in Burton et al. (2006). In short, the recovered sulfide was oxidised to elemental sulfur by an excess amount of $0.0250 \mathrm{M}$ iodine in an acidic solution:

$$
\mathrm{S}_{(\mathrm{l})}^{2-}+\mathrm{I}_{2(\mathrm{l})} \stackrel{\mathrm{H}^{+1}}{\rightarrow} \mathrm{S}_{0_{(\mathrm{s})}}+2 \mathrm{I}_{(\mathrm{l})}^{-}
$$

The unreacted iodine was then measured by titrating with a $0.0125-0.0250 \mathrm{M}$ thiosulfate solution until a colourless endpoint was achieved. The molarity of the thiosulfate solution was known, and the molarity of the iodine solution was determined by titrating with thiosulfate, as 1 moles of thiosulfate reacts with 1 moles of iodine solution. By using a thiosulfate solution with a lower molar concentration, the accuracy of the titration was increased which enabled more precise determination of sulfidic $S$ at low $(\sim 0.05 \%)$ concentrations. In this study a thiosulfate solution with a molarity of 0.0250 was used to determine sulfidic $S$ at concentrations above $1 \%$, and for samples with $<1 \%$ sulfidic $S$ a thiosulfate solution with a molarity of 0.0125 was used.

\subsubsection{Alternative sulfur speciation setup}

A complete recovery of all operationally defined reduced inorganic sulfur species can be performed using the same reagents and procedures previously published (e.g. Fossing \& Jørgensen, 1989; Backlund \& Boman et al., 2005).

After completed AVS extraction (1-2 h), the $\mathrm{HCl}$ supernatant can be removed by centrifugation (10 minutes at $3000 \mathrm{rpm}$ ) and elemental sulfur extracted by stirring the sample with $10 \mathrm{~mL}$ of acetone for 16-24 hours. The supernatant is removed by centrifugation and the sample is washed 


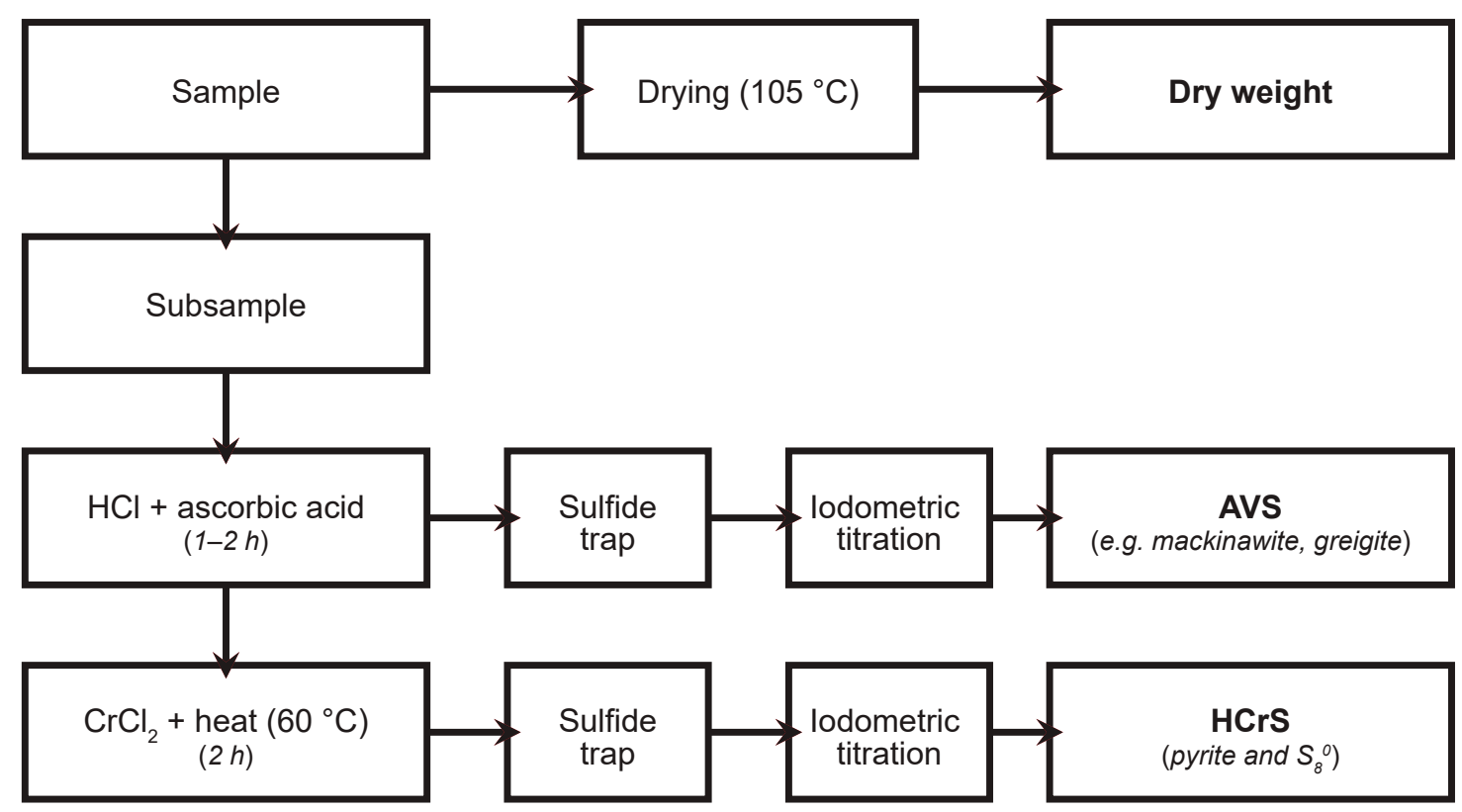

Figure 3. Flowchart for the simplified sequential distillation method used in this study for the determination of AVS-S and HCrS-S.

and centrifuged an additional two times with $5 \mathrm{~mL}$ acetone. According to Wieder et al. (1985), acetone is a polar aprotic solution and is effective for extracting elemental sulfur from soil samples. A yellow precipitate of elemental sulfur will be visible after evaporating the acetone solution and can be dissolved using $10 \mathrm{~mL}$ of filtered $(0.2 \mu \mathrm{m})$ $3 \mathrm{M} \mathrm{CrCl}_{2}$-solution with distillation at $60{ }^{\circ} \mathrm{C}$ for 1-2 hours.

Pyrite-S can subsequently be determined on the initial sample using filtered $(0.2 \mu \mathrm{m}) 10 \mathrm{~mL} 3 \mathrm{M}$ $\mathrm{CrCl}_{2}$ for a modern, newly formed pyrite fraction at room temperature $(\mathrm{CCrS})$ for approximately 5 hours, followed by heating at $60^{\circ} \mathrm{C}$ for $2-3$ hours for an older, more mature and stable pyrite fraction ( $\mathrm{HCrS})$, or directly with distillation at $60{ }^{\circ} \mathrm{C}$ $(2-3 \mathrm{~h})$ for a combined pyrite-S fraction (Backlund $\&$ Boman et al., 2005; Duan et al., 1997). If elemental sulfur is not removed after AVS, it will be included in the HCrS fraction, as heating and a strong reducing agent is required to break apart the strong covalent cyclo-octasulfur $\left(\mathrm{S}_{8}{ }^{0}\right)$ rings (Fossing $\&$ Jørgensen, 1989). For total reducible sulfur (TRS, i.e. including AVS, $\mathrm{HCrS}$ and ES), $10-20 \mathrm{~mL}$ of $3 \mathrm{M} \mathrm{CrCl}_{2}$ and distillation at $60{ }^{\circ} \mathrm{C}$ will extract all reduced inorganic sulfur species with an oxidation state of less than +6 in 2-3 hours.

\subsection{Other analyses}

Homogenised soil and peat subsamples were measured in duplicates with ICP-OES for total aqua regia leachable sulfur. Subsamples were ovendried in quadruplets to constant weight at $105^{\circ} \mathrm{C}$ for 12-24 hours for dry weight determinations followed by loss-on-ignition (LOI) by combustion in $550^{\circ} \mathrm{C}$ for $4 \mathrm{~h}$ according to Heiri et al. (2001). Subsamples were incubated for 16 weeks at room temperature $\left(-20^{\circ} \mathrm{C}\right)$ and kept at near field capacity moistness (adjusted with deionised water when necessary) according to the method by Creeper et al. (2012). The field $\mathrm{pH}$ and 16-week incubation $\mathrm{pH}$ were measured with Hamilton flatrod electrodes. This method by Creeper et al. (2012) is routinely used for identification and characterisation of AS soils. 


\section{Results and discussion}

\subsection{Quality assessment: recovery of sulfide from pure reagents}

The recovery of $S$ from pure pyrite standards was close to $1: 1\left(r^{2}=0.9995\right)$ with a rate between 91$101 \%$ and a relative standard deviation (RSD) of $1.1-2.9 \%$ (Fig. 4 and Table 1). This is in line with recoveries reported in previous methods by e.g. Backlund \& Boman et al., (2005), Burton et al. (2008) and Gröger et al. (2009). Higher $S$ concentrations yield lower recovery rates which may be due to the trapping solution becoming saturated at high concentrations. Nevertheless, the precision is still remarkably good even at $-5 \%$ S concentrations.

Determined sulfide concentrations by AVS distillation $(38.4 \mathrm{mg} / \mathrm{L} ; \mathrm{RSD}=0.026 \%)$ in the SAOB sulfide standard solution was close to the actual concentrations (Fig. 5) determined by the sulfide electrode $(34.7 \mathrm{mg} / \mathrm{L} ; \quad \mathrm{RSD}=0.008 \%$; $\mathrm{n}=3)$. The relatively large standard deviation for the recovery of low amounts of sulfide $(0.034 \mathrm{mg}$;

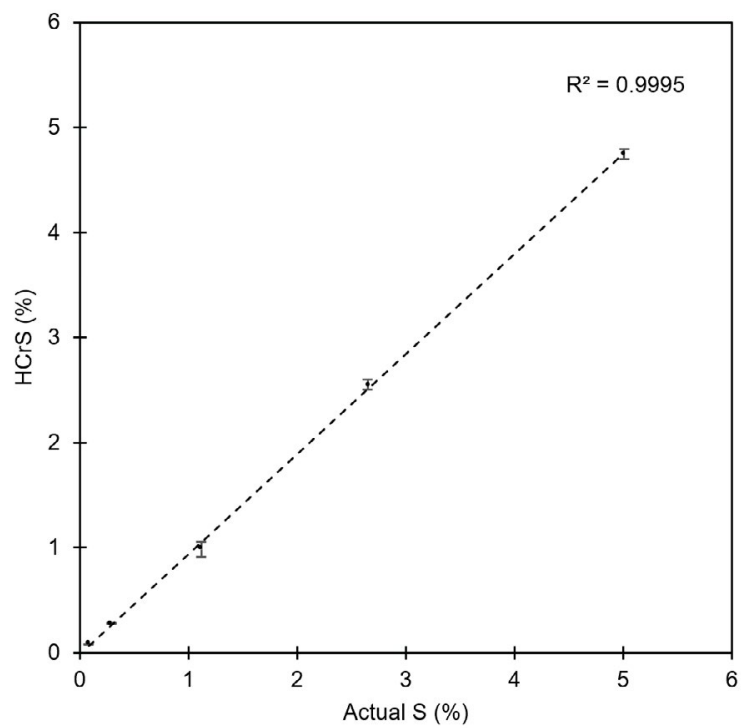

Figure 4. S concentration in laboratory grade pyrite and talc mixtures $(44 \mu \mathrm{m})$ versus measured $\mathrm{S}$ from a 3-hour hot chromium reducible sulfur ( $\mathrm{HCrS}$ ) distillation. Error bars indicating Standard Deviation ( $n=4$; one outlier removed).
Table 2) is due to the resolution of the titration vessel with the current thiosulfate and iodine solution. One drop (c. $0.05 \mathrm{~mL}$ ) of M 0.0125 thiosulfate correspond to roughly $0.01 \mathrm{mg}$ of sulfide. If necessary, the precision can be increased either by using more dilute titrants or a larger sample size. For the higher sulfide concentrations, $0.169 \mathrm{mg}$ and $0.507 \mathrm{mg}$, on the other hand, sulfide recovery RSD was $<10 \%$ (Table 2).

An estimation of the apparatus background static was determined by going through the distillation steps with just the reagents (blank). The estimation of the background error of the pyrite standards was determined by going through the distillation steps with the reagents on the laboratory grade talc without added pyrite (method blank). The LoD (0.002\%) and LoQ (0.006\%) for the simplified distillation sulfur speciation method were calculated (Eq I) based on the method blank and on the slope of the regression line from the pyrite standard experiments (Table $1 \&$ Fig. 4). Experiments with the SAOB show that detection of ultra-low sulfide concentrations is indeed possible (Table 2 \& Fig. 5).

Table 1. Recovery of S from laboratory grade pyrite and talc mixtures determined in quadruplicates using the hot chromium reducible sulfur $(\mathrm{HCrS})$ method.

\begin{tabular}{llll}
$\mathrm{S}^{\mathrm{a}}(\%)$ & $\mathrm{HCrS}(\%)$ & $\mathrm{RSD}(\%)$ & Recovery $(\%)$ \\
\hline n.a. & $0.000 \pm 0.000^{\mathrm{b}}$ & n.a. & n.a. \\
$0.018^{\mathrm{c}}$ & $0.025 \pm 0.001$ & 2.9 & $137 \pm 4$ \\
0.081 & $0.082 \pm 0.002$ & 2.2 & $101 \pm 2$ \\
0.295 & $0.281 \pm 0.006$ & 2.0 & $95 \pm 2$ \\
1.120 & $0.984 \pm 0.072$ & 7.3 & $91 \pm 3$ \\
2.650 & $2.553 \pm 0.047$ & 1.8 & $96 \pm 2$ \\
5.010 & $4.746 \pm 0.051^{\mathrm{d}}$ & 1.1 & $95 \pm 1^{\mathrm{d}}$ \\
\hline
\end{tabular}

${ }^{a}$ actual total (aqua regia) $S$ concentration in pyrite-talc mixture

${ }^{\mathrm{b}}$ no sample, only HCrS reagents

${ }^{\mathrm{c}}$ talc without added pyrite (method blank)

d one outlier removed

$\pm=$ Standard Deviation

$\mathrm{RSD}=$ Relative Standard Deviation 
Table 2. Recovery of sulfide from a $34.7 \mathrm{mg} / \mathrm{L}$ (standard deviation $0.003 \mathrm{mg} / \mathrm{L}$ ) sulfide standard SAOB solution using varying volumes of SAOB sulfide standard solution. Analyses made in quadruplicates using the AVS method.

\begin{tabular}{llllll}
\hline S conc. in solution $(\mathrm{mg} / \mathrm{L})$ & Volume of solution $(\mathrm{mL})$ & actual $(\mathrm{mg})$ & recovered $(\mathrm{mgAVS})$ & $\mathrm{RSD}(\%)$ & $\%$ recovery \\
\hline $0^{\mathrm{a}}$ & n.a. & $0^{\mathrm{a}}$ & 0 & n.a. & n.a. \\
$34.7 \pm 0.003$ & 1.02 & 0.034 & $0.048 \pm 0.013$ & 27.3 & $139 \pm 38$ \\
$34.7 \pm 0.003$ & 5.05 & 0.169 & $0.188 \pm 0.008$ & 4.42 & $111 \pm 5$ \\
$34.7 \pm 0.003$ & 15.1 & 0.507 & ${ }^{\mathrm{b}} 0.474 \pm 0.051$ & 10.7 & $\mathrm{~b} 94 \pm 1$ \\
\hline
\end{tabular}

${ }^{a}$ no sample, only AVS reagents

${ }^{\mathrm{b}}$ one outlier removed

$\pm=$ Standard Deviation

$\mathrm{RSD}=$ Relative Standard Deviation

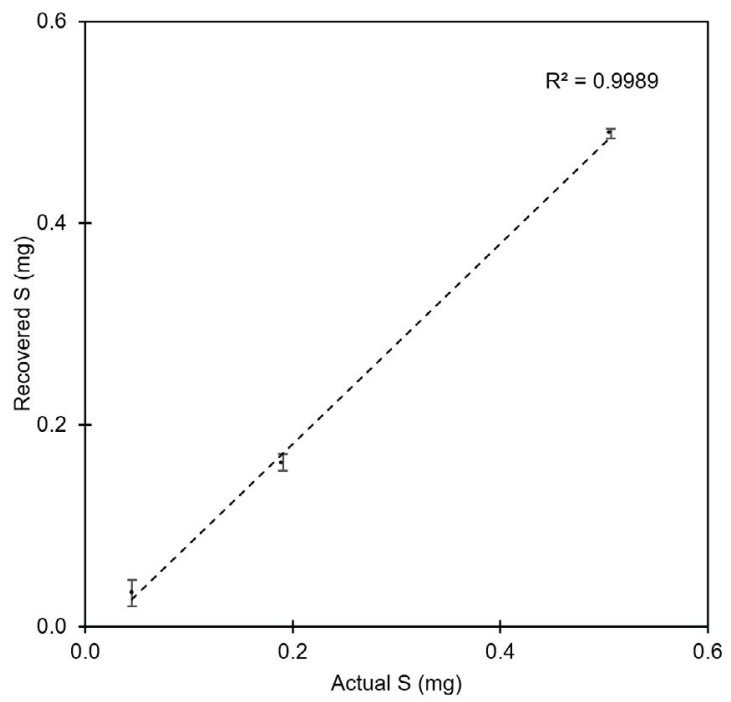

Figure 5. The amount of sulfide in the SAOB sulfide standard solution versus measured sulfide after a 2-hour AVS distillation. Error bars indicating Standard Deviation ( $n=4$; one outlier removed).

Fitzpatrick et al. (2017) indicated a detection limit of $0.005 \%$ for the conventional diffusionbased CRS method. The results of the simplified distillation method with the current setup are thus comparable with established methods and well within limits $(\geq 0.01 \%)$ for detecting and quantifying sulfides in hypersulfidic materials; and by using a larger sample size (more S) and/ or using a more dilute thiosulfate and iodine solution (better titration resolution), the theoretical limits of detection and quantitation can easily be significantly improved if necessary. Due to its superb accuracy, the iodometric titration is preferable to the gravimetric approach used by e.g. Backlund \& Boman et al. (2005). Moreover, in contrast to the colorimetric procedure used by e.g. Allen et al. (1993) and Gröger et al. (2009) or the potentiometric lead perchlorate method (used in this study when determining the precise sulfide concentration in the SAOB), it does not require any specialised apparatus.

\subsection{Determination of reduced inorganic sulfur species from natural sulfidic soil materials}

All materials were classified as hypersulfidic; the 16-week incubation $\mathrm{pH}$ dropped under 4 ( $<3$ for peat) and the inorganic sulfide concentration was above $0.01 \%$ in all samples. Table 3 lists the results of AVS-S and HCrS-S analyses with comparison to the total aqua regia leachable $S$ analysed by ICP-OES. Most of the $S$ was in sulfide form but the peat sample contained considerable amount of other sulfur species, most likely organic sulfur, than those quantified as AVS and HCrS (Table 3). The silty gyttja-clay consisted primarily of pyrite ( $\mathrm{HCrS}-0.61 \%)$ and had the highest concentration of AVS-S $(-0.14 \%)$. The RSD was $2.7 \%$ for AVS and $2.1 \%$ for HCrS. The coarse silt and the sand on the other hand had barely detectable AVS-S (0.008 $\%$ ) with an RSD of $25.0 \%$ and $11.8 \%$, respectively, 
and a low concentration $(0.047 \%$ and $0.050 \%)$ of $\mathrm{HCrS}-\mathrm{S}(\mathrm{RSD}=12.4 \%$ and $5.1 \%)$. The larger RSD in particularly the AVS step for these materials could be partly explained by low amounts of AVS and a large titration error. The AVS-S concentration in the peat sample was likewise very low $(0.008 \%)$ with an RSD of $28.7 \%$. It had the highest total inorganic sulfide content, however, with nearly $1 \% \mathrm{HCrS}-\mathrm{S}$ $(\mathrm{RSD}=2.2 \%)$. The method precision decrease at low $S$ concentrations for natural sulfidic material but is nevertheless remarkably good for material with high sulfide content. Heterogeneities within the natural samples are likely to explain some of the relatively high RSD. The impact of sample weight was tested with a range of $-300-5000 \mathrm{mg}$ (dry weight equivalent) sample sizes, but no correlation was found between sample size and recovered $S$. The method is therefore robust for soil, sediment and peat material, and the sample size can thus be varied in order to improve recovery amounts for materials with low $S$ concentrations.

Table 3. Determination of acid volatile sulfur (AVS) and hot chromium reducible sulfur (HCrS) from hypersulfidic geological material.

\begin{tabular}{cccccccccc}
\hline sample & material & LOI (\%) & field pH & 16winc. pH & $\mathrm{S}^{\mathrm{a}}(\%)$ & AVS $^{\mathrm{b}}(\%)$ & $\mathrm{RSD}(\%)$ & $\mathrm{HCrS}^{\mathrm{b}}(\%)$ & $\mathrm{RSD}(\%)$ \\
\hline a & gyttja-clay & 6.4 & 7.1 & 3.2 & 0.535 & $0.388 \pm 0.007$ & 1.7 & $0.157 \pm 0.009$ & 5.5 \\
b & silty gyttja-clay & 4.5 & 8.0 & 2.8 & 0.852 & $0.144 \pm 0.004$ & 2.7 & $0.615 \pm 0.013$ & 2.1 \\
C & coarse silt & 0.5 & 5.9 & 3.3 & 0.066 & $0.008 \pm 0.002$ & 25 & $0.047 \pm 0.006$ & 12.4 \\
d & sand & 0.2 & 7.6 & 3.0 & 0.054 & $0.008 \pm 0.001$ & 11.8 & $0.050 \pm 0.003$ & 5.1 \\
e & peat & 79.2 & 4.4 & 2.5 & 1.780 & $0.019 \pm 0.005$ & 28.7 & $0.991 \pm 0.022$ & 2.2 \\
\hline
\end{tabular}

a actual total (aqua regia) S concentration

${ }^{\mathrm{b}} \mathrm{n}=4$

$\pm=$ Standard Deviation

RSD = Relative Standard Deviation

\subsection{Advantages and limitations of the simplified sulfur speciation method}

Traditionally sulfur speciation methods-distillation as well as diffusion-require specialised glassware that often demand a significant amount of bench space, are laborious to use and clean and need careful handling. The method proposed by Burton et al. (2008) demonstrated that sulfur speciation can also be done using more simple and inexpensive equipment, whilst still achieving similar recovery rates. Prolonged reaction times, however, proved to be a disadvantage in comparison with distillation methods when rapid analyses were required. The simplified distillation method for sulfur speciation meets the same requirements for recovery rates as previous methods and is constructed from similarly inexpensive material and offers significantly shorter reaction times. Samples with high pyrite content might require longer reaction times, but since the reaction vessels can be submerged in a heated water bath, the reaction times for $\mathrm{HCrS}$ are much faster than for cold distillations. The method has defined limits of detection and quantitation that are seldom published but sorely needed, especially with regards to problematic soils with low sulfidic-S content.

The simple diffusion method (Burton et al., 2008) has also proven problematic for analysing samples low in density, such as peat and highly organic rich material, as the material does not become thoroughly mixed with the reagent on an orbital shaker. Sequential analysis is also problematic since sample residue can stick to the walls of the collection vessel inside the reaction vessel. With the simplified distillation method 
magnetic stirring can be used to ensure thorough mixing, and the $\mathrm{N}_{2(\mathrm{~g})}$ carrier gas also bubbles through the reagent/sample slurry, ensuring that the liberated $\mathrm{H}_{2} \mathrm{~S}_{(\mathrm{g})}$ is fully extracted. As hypersulfidic peat has proven to pose a large environmental risk, it is important to be able to quantify the acidity producing capacity of such materials.

Sample size did not affect the sulfur recovery. However, with large samples, $S$ concentrations in the trapping solution may become saturated and with too small samples, $S$ concentrations may be under the detection limit. These issues can be avoided by varying the sample size $(-300-5000 \mathrm{mg}$ dry weight equivalent). Generally, larger sample portions of heterogenous materials is recommended to increase precision. Large sample volumes with high carbonate content may also neutralise the added reagents, in which case stronger acids might be needed.

\section{Conclusions}

The results of this study showed that sulfur speciation can be conducted using simple inexpensive equipment, whilst still achieving good precision (RSD $\leq 3 \%$ ), with recovery (91-101\%) similar to published results with conventional methods. Limits of determination $(0.002 \%)$ and quantitation $(0.006 \%)$ were remarkably low and can easily be further lowered by adjusting sample size or by dilution of titration solutions. With the simplified distillation setup used, it was possible to analyse several samples simultaneously and achieve much faster reaction times than with corresponding diffusion methods. In contrast to diffusion methods, the method was also suitable for low density materials such as peat.

\section{Acknowledgements}

This study has been a part of the TUNNISTUS project which is funded by the European Regional Development Fund 2017-2020.

\section{References}

Allen, H. E., Fu, G. \& Deng, B., 1993. Analysis of acid-volatile sulfide (AVS) and simultaneously extracted metals (SEM) for the estimation of potential toxicity in aquatic sediments. Environmental Toxicology and Chemistry 12, 1441-1453. https://doi.org/10.1002/etc.5620120812

Andriesse, W. \& Van Mensvoort, M. E. F., 2006. Acid sulfate soils: distribution and extent. Encyclopedia of soil science 1, 14-19.

American Public Health Association (APHA), 1976. Standard Methods for the Examination of Water and Wastewater. (14. Ed.). American Public Health Association, 1193 p.

Backlund, K., Boman, A., Fröjdo, S. \& Åström, M., 2005. An analytical procedure for determination of sulphur species and isotopes in boreal acid sulphate soils and sediments. Agricultural and Food Science 14, 70-82. https://doi.org/10.2137/1459606054224147

Boman, A., Åström, M. \& Fröjdö, S., 2008. Sulfur dynamics in boreal acid sulfate soils rich in metastable iron sulfidethe role of artificial drainage. Chemical Geology 255, 68-77. https://doi.org/10.1016/j.chemgeo.2008.06.006

Burton, E., Sullivan, L. A., Bush, R. T., Johnston, S. G. \& Keene, A. F., 2008. A simple and inexpensive chromiumreducible sulfur method for acid-sulfate soils. Applied Geochemistry 23, 2759-2766. https://doi.org/10.1016/j.apgeochem.2008.07.007

Canfield, D. E., Raiswell, R., Westrich, J. T., Reaves, C. M. \& Berner, R. A., 1986. The use of chromium reduction in the analysis of reduced inorganic sulfur in sediments and shales. Chemical geology 54, 149-155.

https://doi.org/10.1016/0009-2541(86)90078-1

Creeper, N., Fitzpatrick, R. \& Shand, P., 2012. A simplified incubation method using chip-trays as incubation vessels to identify sulphidic materials in acid sulphate soils. Soil use and management 28, 401-408. https://doi.org/10.1111/j.1475-2743.2012.00422.x

Dalhem, K., Engblom, S., Stén, P. \& Österholm, P., 2019. Subsurface hydrochemical precision treatment of a coastal acid sulfate soil. Applied Geochemistry 100, 352-362.

https://doi.org/10.1016/j.apgeochem.2018.12.005

Duan, W. M., Coleman, M. L. \& Pye, K., 1997. Determination of reduced sulphur species in sediments - an evaluation and modified technique. Chemical Geology 141, 185194.

https://doi.org/10.1016/S0009-2541(97)00062-4

Fitzpatrick, R. W., Mosley, L. M. \& Cook, F. J., 2017. Understanding and Managing Irrigated Acid Sulfate and Salt-affected Soils: A handbook for the Lower Murray Reclaimed Irrigation Area. University of Adelaide Press, 139 p. https://doi.org/10.1017/10.20851/murray-soils 
Fossing, H. \& Jørgensen, B.B. ,1989. Measurement of bacterial sulphate reduction in sediment: evaluation of a singlestep chromium reduction method. Biogeochemistry 8 , 205-222. https://doi.org/10.1007/BF00002889

Glaister, M. G., Moody, G. J., Nash, T. \& Thomas, J. D. R., 1984. The stability of sulphide anti-oxidant buffer. Analytica Chimica Acta 165, 281-284. https://doi.org/10.1016/S0003-2670(00)85211-3

Gröger, J., Franke, J., Hamer, K. \& Schulz, H. D., 2009. Quantitative Recovery of Elemental Sulfur and Improved Selectivity in a Chromium-Reducible Sulfur Distillation. Geostandards and Geoanalytical Research 33, 17-27. https://doi.org/10.1111/j.1751-908X.2009.00922.x

Heiri, O., Lotter, A. F. \& Lemcke, G., 2001. Loss on ignition as a method for estimating organic and carbonate content in sediments: reproducibility and comparability of results. Journal of paleolimnology 25, 101-110. https://doi.org/10.1023/A:1008119611481

Hsieh, Y.P. \& Yang, C.H., 1989. Diffusion methods for the determination of reduced inorganic sulfur species in sediments. Limnology and Oceanography 34, 11261130 . https://doi.org/10.4319/lo.1989.34.6.1126

Hsieh, Y.-P., Chung, S.-W., Tsau, Y.-J. \& Sue, C.-T., 2002. Analysis of sulfides in the presence of ferric minerals by diffusion methods. Chemical Geology 182, 195-201. https://doi.org/10.1016/S0009-2541(01)00282-0

Isbell, R. F. \& National Committee on Soil and Terrain, 2016. The Australian Soil Classification, $2^{\text {nd }}$ Ed. CSIRO Publishing, $152 \mathrm{p}$. https://doi.org/10.1071/9781486304646

IUSS Working Group WRB, 2015. World Reference Base for Soil Resources 2014, update 2015 International soil classification system for naming soils and creating legends for soil maps. World Soil Resources Reports No. 106, $192 \mathrm{p}$.
Kirby, C. S. \& Cravotta III, C. A., 2005. Net alkalinity and net acidity 1: theoretical considerations. Applied Geochemistry 20, 1920-1940.

https://doi.org/10.1016/j.apgeochem.2005.07.002

Mattbäck, S., Boman, A. \& Österholm, P., 2017. Hydrogeochemical impact of coarse-grained post-glacial acid sulfate soil materials. Geoderma 308, 291-301. https://doi.org/10.1016/j.geoderma.2017.05.036

Nordmyr, L., Boman, A., Åström, M. \& Österholm, P., 2006. Estimation of leakage of chemical elements from boreal acid sulphate soils. Boreal environment research 11, 261273.

Rickard, D. \& Morse, J. W. 2005. ,Acid volatile sulfide (AVS). Marine chemistry, 97, 141-197. https://doi.org/10.1016/j.marchem.2005.08.004

Shrivastava, A. \& Gupta, V. B., 2011. Methods for the determination of limit of detection and limit of quantitation of the analytical methods. Chronicles of Young Scientists 2(1), $21 \mathrm{p}$. https://doi.org/10.4103/2229-5186.79345

Singer, P. C. \& Stumm, W., 1970. Acidic mine drainage: the rate-determining step. Science 167, 1121-1123. https://doi.org/10.1126/science.167.3921.1121

Sullivan, L. A., Fitzpatrick, R. W., Bush, R. T., Burton, E. D., Shand, P. \& Ward, N. J., 2010. The classification of acid sulfate soil materials: further modifications. Southern Cross GeoScience Technical Report, pp. 1-12.

Wieder, R.K., Lang, G.E. \& Granus, V.A., 1985. An evaluation of wet chemical methods for quantifying sulfur fractions in freshwater wetland peat. Limnology and Oceanography 30, 1109-1115. https://doi.org/10.4319/lo.1985.30.5.1109

Zhabina, N. N. \& Volkov, I. I., 1978. A method of determination of various sulfur compounds in sea sediments and rocks. In: Krumbein, W.E. (Ed.), Environmental Biogeochemistry and Geomicrobiology. Ann Arbor Science Publishers, Michigan, pp. 735-745. 